LAWRENCE LIVERMORE N A T IO N A L LABORATORY
Omega Dante Soft X-Ray Power Diagnostic Component Calibration at the National Synchrotron Light Source

K.M. Campbell, F.A. Weber, E.L. Dewald, S.H. Glenzer, O.L. Landen, R.E. Turner, P.A. Waide

April 16, 2004

15th Topical Conference on High Temperature Plasma Diagnostics San Diego, CA, United States April 19, 2004 through April 22, 2004 
This document was prepared as an account of work sponsored by an agency of the United States Government. Neither the United States Government nor the University of California nor any of their employees, makes any warranty, express or implied, or assumes any legal liability or responsibility for the accuracy, completeness, or usefulness of any information, apparatus, product, or process disclosed, or represents that its use would not infringe privately owned rights. Reference herein to any specific commercial product, process, or service by trade name, trademark, manufacturer, or otherwise, does not necessarily constitute or imply its endorsement, recommendation, or favoring by the United States Government or the University of California. The views and opinions of authors expressed herein do not necessarily state or reflect those of the United States Government or the University of California, and shall not be used for advertising or product endorsement purposes.

This work was performed under the Auspices of the U.S. Department of Energy by the University of California, Lawrence Livermore National Laboratory under Contract No. W-7405-Eng-48. 


\title{
Omega Dante Soft X-Ray Power Diagnostic Component Calibration at the National Synchrotron Light Source*
}

\author{
K.M. Campbell, F.A. Weber, E.L. Dewald, S.H. Glenzer, O.L. Landen, R.E. Turner, P.A. Waide
}

The Dante soft x-ray spectrometer installed on the Omega laser facility at the Laboratory for Laser Energetics, University of Rochester is a twelve-channel filter-edge defined xray power diagnostic. It is used to measure the absolute flux from direct drive, indirect drive (hohlraums) and other plasma sources. Calibration efforts using two beam lines, $\mathrm{U} 3 \mathrm{C}(50 \mathrm{eV}-1 \mathrm{keV})$ and X8A (1keV-6keV) at the National Synchrotron Light Source (NSLS) have been implemented to insure the accuracy of these measurements. We have calibrated vacuum $\mathrm{x}$-ray diodes, mirrors and filters.

\section{$\underline{\text { Introduction }}$}

Design and optimization of ICF indirect drive experiments relies on many factors. One key parameter is the measurement of the absolute radiation drive flux inside the hohlraum. This has been accomplished on Nova and Omega with the Dante soft x-ray spectrometer, DMX, and diamond PCDs. With the ability to measure the absolute soft Xray flux for photon energies up to $3 \mathrm{keV}$ we can determine material $\mathrm{x}$-ray albedo, laser to $\mathrm{X}$-ray conversion efficiency and the characteristic blackbody temperature.

This device is a collection of x-ray absorption edge filter defined 'channels' (see table 1) that consist of collimators, edge filters, grazing angle mirrors (for high energy discrimination on channels $<500 \mathrm{eV}$ ), planar x-ray diodes (XRD), cables, attenuators, and digitizers.

\begin{tabular}{|l|l|l|l|l|l|l|l|l|l|l|l|l|}
\hline Ch\# & 1 & 2 & 3 & 4 & 5 & 6 & 7 & 8 & 9 & 10 & 11 & 12 \\
\hline $\begin{array}{l}\text { Spectral } \\
\text { Region } \\
(\mathrm{eV})\end{array}$ & 150 & -250 & 450 & 750 & 900 & 980 & 1200 & 1300 & 1600 & 2000 & 50 & 90 \\
\hline $\begin{array}{l}\text { XRD } \\
\text { Cathode }\end{array}$ & $\mathrm{Al}$ & $\mathrm{Al}$ & $\mathrm{Cr}$ & $\mathrm{Cr}$ & $\mathrm{Ni}$ & $\mathrm{Ni}$ & $\mathrm{Ni}$ & $\mathrm{Ni}$ & $\mathrm{Al}$ & $\mathrm{Al}$ & $\mathrm{Cr}$ & $\mathrm{Cr}$ \\
\hline Mirror & $\begin{array}{l}\text { Carbon } \\
\theta=5^{\circ}\end{array}$ & $\begin{array}{l}\mathrm{Be} \\
\theta=3.5^{\circ}\end{array}$ & $\begin{array}{l}\text { Carbon } \\
\theta=2.5^{\circ}\end{array}$ & & & & & & & & $\begin{array}{l}\text { Carbon } \\
\theta=7^{\circ}\end{array}$ & $\begin{array}{l}\text { Carbon } \\
\theta=5^{\circ}\end{array}$ \\
\hline $\begin{array}{l}\text { Filter } \\
\text { Material }\end{array}$ & $\mathrm{B}$ & $\mathrm{C}$ & $\mathrm{V}$ & $\mathrm{Co}$ & $\mathrm{Cu}$ & $\mathrm{Zn}$ & $\mathrm{Mg}$ & $\mathrm{Al}$ & $\mathrm{Si}$ & $\begin{array}{l}\mathrm{C}, \\
\mathrm{Fe}, \\
\mathrm{Cr}\end{array}$ & $\mathrm{Al}$ & $\mathrm{Be}$ \\
\hline
\end{tabular}

Table 1: Omega Dante channel configurations and channel band-pass.

The voltage signals from the experiments are analyzed using measured response functions for each channel to convert voltage to $\mathrm{GW} / \mathrm{sr} / \mathrm{eV}$, which is used to fit each point to a Planckian spectrum to calculate the flux.

Each channel has a characteristic spectral response depending on the absorption of the filters that depends on material thickness and $\mathrm{Z}$, the reflectivity of the mirrors and the response of the XRDs. These values have to be carefully measured in order to calculate the radiation output of the hohlraum to $\pm 20 \%$ or better. We calibrate all three elements on two beam lines at the National Synchrotron Light Source (NSLS) at Brookhaven National Lab (BNL). These two beam lines allow us to accurately select photon energy 
from $60 \mathrm{eV}$ up to $6 \mathrm{keV}$. The bandwidth depends on the selected energy with an average FWHM of $3 \mathrm{eV}$ and a spectral purity of $1 \%$.

\section{$\underline{\text { X-Ray Diodes }}$}

The Dante installed on Omega has ten main channels and two low energy channels (< $110 \mathrm{eV}$ ). The XRDs are planar vacuum diodes with aluminum, nickel or chrome cathodes biased at $5 \mathrm{kV}$ while in use. Each diode is used for a specific channel so that the calibration energy scans on the XRD can be customized to best characterize the spectral range of that channel.

The calibration procedure consists of mounting the XRD inline with the synchrotron beam and with an absolutely calibrated silicon x-ray diode. The XRD is biased at 30 VDC, not the operation level of 5KV during these tests for safe operation. The low bias does reduce the temporal response and saturation level, however at synchrotron fluences of approximately $10^{9}$ photons $/ \mathrm{cm}^{2} / \mathrm{s}$, we do not operate in the saturated regime and we do not measure the temporal response. The number of photoelectrons released and measured depends on the anode material and photon wavelength, not the bias voltage, provided the voltage remains below the field ionization potential. Additionally, the dark current for the $\mathrm{XRDs}$ is of the order $100 \mathrm{fA}$ and the measured signal is tens of $\mu \mathrm{A}$. Therefore the error introduced in extrapolating from $30 \mathrm{~V}$ to $5 \mathrm{kV}$ is dwarfed by other errors and are of the order $10^{-4}$. Each detector is connected in series with a Keithley current meter whose outputs are read by a PC that also performs the task of calculating the XRD sensitivity at each photon energy from the measured current and the known Si AXUV sensitivity using the following formula:

$$
\mathrm{S}_{\mathrm{XRD}}=\mathrm{S}_{0}\left(\mathrm{I}_{\mathrm{XRD}}-\mathrm{I}_{\mathrm{XRDdark}}\right) /\left(\mathrm{I}_{0}-\mathrm{I}_{\text {dark }}\right) .
$$

where $S_{0}$ is the known silicon AXUV sensitivity in A/MW, $I_{\text {dark }}$ is the measured silicon dark current, $\mathrm{I}_{\mathrm{xrddark}}$ is the measured XRD dark current, $\mathrm{I}_{0}$ is the measured silicon current, $\mathrm{I}_{\mathrm{xrd}}$ is the measured XRD current.

Photon energy selection is accomplished with a Si multi-layer crystal (from $1 \mathrm{keV}-2$ $\mathrm{keV}$ ), a double $\mathrm{Si}$ crystal (from $2.1 \mathrm{keV}-6 \mathrm{keV}$ ) or grating monochrometer $(60 \mathrm{eV}-$ $1 \mathrm{KeV}$ ) and edge filters resulting in an average, energy dependent FWHM of $3 \mathrm{eV}$ for the incident radiation.

The primary set of XRDs was calibrated in 1993 at the NSLS, then again in 1998 at the LURE facility in France. Between these calibrations, all of the XRDs showed a decrease in response (measured in A/MW). In November 2001 the primary set was again calibrated at the NSLS and again, the response was lower than the previous measurement, following the trend of degradation over time. This trend is not apparent in the subsequent measurements made six months apart since November 2001. This would indicate that the diodes degrade with use over years and not months and is most likely caused by surface contamination as evidenced by the carbon and oxygen absorption edges seen in Figure 1. 


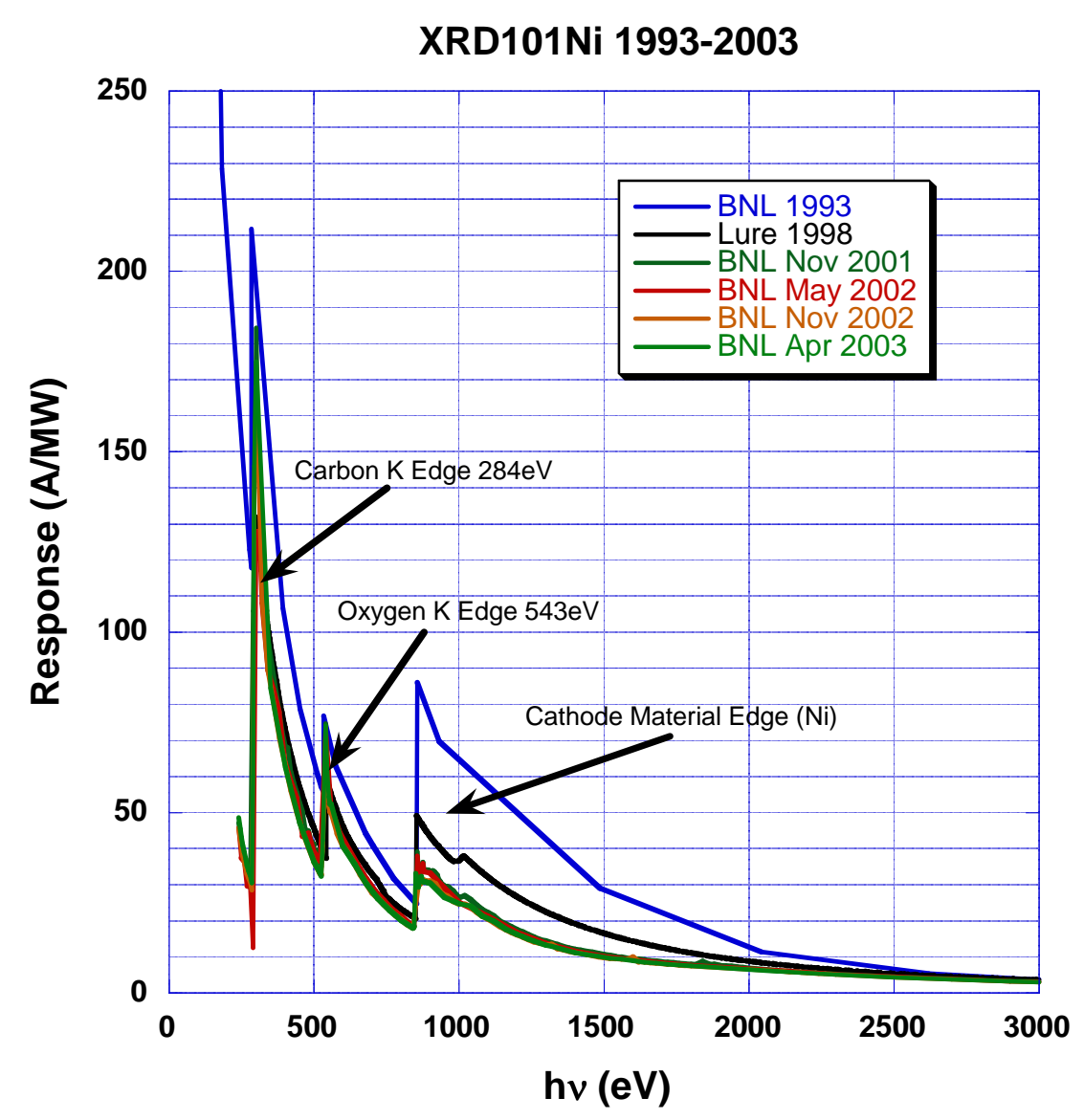

Figure1: Ni Cathode XRD spectral response showing contamination edges and reduction in absolute response over time.

\section{$\underline{\text { Mirrors }}$}

Grazing incidence mirrors are used on channels 1, 2, 3, 11 and $12(<520 \mathrm{eV})$ for highenergy discrimination. There are eight mirrors, $6 \mathrm{C}$ and $2 \mathrm{Be}$, set at 4 different angles: $2.5^{0}, 3.5^{0}$ (Be only), $5^{0}$ and $7^{0}$. The calibration procedure consists of several steps. First, an XRD is calibrated on beam line $\mathrm{U} 3 \mathrm{C}$ as described above. Then, the mirror is installed on the beam line with a diode laser mounted coaxial in a XRD body. The mirror is then moved to reflect the laser beam through two pinholes that are collinear with the synchrotron beam. (See figure 2).

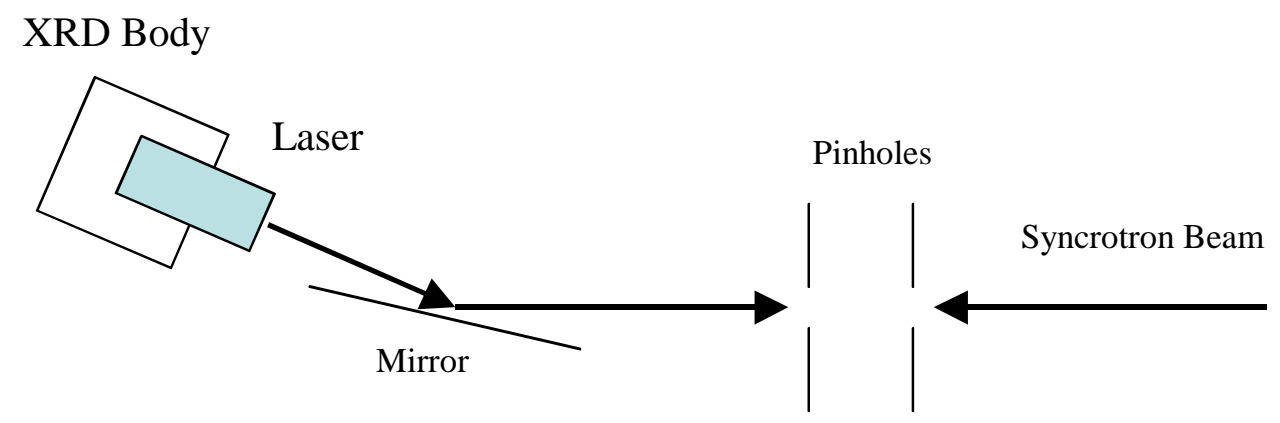

Figure 2: Mirror Alignment 
After alignment, the XRD is mounted on the mirror housing to measure the reflected $\mathrm{X}$ rays, and another response curve is obtained. This curve is divided by the original response of the $\mathrm{XRD}$, which yields a reflectivity vs. photon energy curve for the mirror. The material absorption edges, i.e. Si L edge, $\mathrm{C}$ and $\mathrm{O} \mathrm{K}$ edges could introduce significant error in the reflectance values. However, we avoid this analytically by carefully measuring below and above the edge then extrapolating to find the average edge value.

The carbon mirrors show an oxygen edge at $538 \mathrm{eV}$ and a suppression of the carbon edge, probably due to absorbed water in the carbon surface. The Be mirrors have carbon edges due to carbon contamination. A reduction in reflectivity is observed in all the mirrors when compared to the BNL data from 1993.

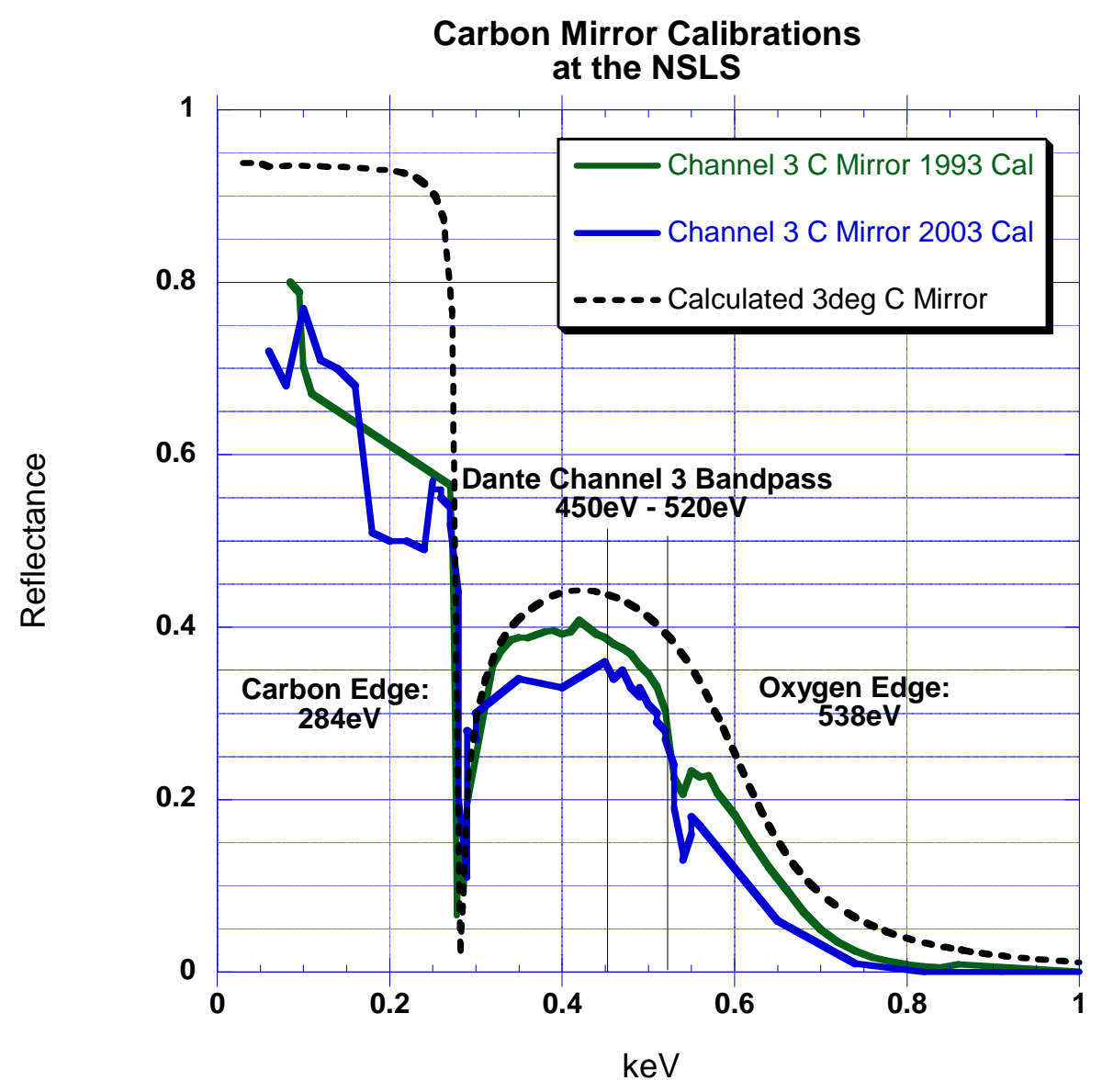

Figure3: Measured mirror reflectance for $2.5 \mathrm{deg}$ carbon mirror typically used at $450 \mathrm{eV}-520 \mathrm{eV}$

\section{$\underline{\text { Filters }}$}

Thin, edge filters are used for channel spectrum definition. They are manufactured to a requested nominal thickness; we then measure their transmittance from $100 \mathrm{eV}$ to $5 \mathrm{keV}$ to 
determine their actual thickness to less than $1 \%$. This is a vast improvement from measuring the transmission on the Henke source where the spectrum is limited in intensity by the anode material and secondary flourescer thus limiting the accuracy of the filter calculation to no better than $10 \%$ for thicker and high $\mathrm{Z}$ material. An error in filter thickness on one channel will not affect all the data in the same way as each measurement is weighted by the blackbody distribution for the characteristic target radiation temperature. For example, a 50\% error on channel one filter thickness will increase the error for $250 \mathrm{eV}$ hohlraums by $1 \%-2 \%$. However, for colder hohlraums $(<150 \mathrm{eV})$ the overestimate was as high as $10 \%$ in flux, which is comparable to the $20 \%$ random error on the calibration.

\section{Calibration Error}

The error in absolute flux for our calibration curves at the NSLS is calculated in the following way. The first is the random flux error with the Keithley electrometer and it is simply the square root of the variance of the ten measurements at each spectral point. The second, more complicated source of error is in the normalization file for the absolutely calibrated Si diode standard. The measured diode response is fit to a model response function using the least squares regression method. This model response function is calculated using several parameters; active region thickness, oxide layer thickness, carbon layer and dead layer thickness, and the diffusion length. The error in the fit is added to the uniformity error of the surface (this contributes most of the error at lower energy) and band gap error in Si (2\%). All four error values are added in quadrature to get the systematic flux error. Filter transmission is measured with a normalized pair of AXUV-100 Si diodes and the mirror reflectance is the ratio of the XRD response before the mirror and the same XRD after the mirror thus removing the systematic flux error from these results. (Table \#2)

\begin{tabular}{|c|c|c|c|c|c|c|c|c|c|c|c|c|}
\hline Channel \# & 11 & 12 & 1 & 2 & 3 & 4 & 5 & 6 & 7 & 8 & 9 & 10 \\
\hline Filter & Al & $\mathrm{Be}$ & B & $\mathrm{C}$ & $\mathrm{V}$ & Co & $\mathrm{Cu}$ & $\mathrm{Zn}$ & $\mathrm{Mg}$ & Al & $\mathrm{Si}$ & $\mathrm{Fe} / \mathrm{Cr} / \mathrm{CH}$ \\
\hline Mean Energy (eV) & 60 & 100 & 165 & 265 & 485 & 785 & 940 & 1015 & 1250 & 1400 & 1700 & 2150 \\
\hline Mirror & $\mathrm{C}$ & $\mathrm{C}$ & $\mathrm{C}$ & $\mathrm{Be}$ & $\mathrm{C}$ & & & & & & & \\
\hline \multicolumn{13}{|l|}{ Systematic flux errors } \\
\hline XRD & $17.4 \%$ & $8.2 \%$ & $11.5 \%$ & $6.0 \%$ & $3.8 \%$ & $2.3 \%$ & $2.3 \%$ & $2.3 \%$ & $2.3 \%$ & $2.3 \%$ & $2.7 \%$ & $2.3 \%$ \\
\hline \multicolumn{13}{|l|}{ Random flux errors } \\
\hline $\mathrm{XRD}$ & $0.4 \%$ & $0.4 \%$ & $0.2 \%$ & $0.2 \%$ & $2.1 \%$ & $0.2 \%$ & $0.2 \%$ & $0.6 \%$ & $0.2 \%$ & $0.3 \%$ & $0.3 \%$ & $1.2 \%$ \\
\hline Mirror & $0.4 \%$ & $0.5 \%$ & $0.6 \%$ & $0.6 \%$ & $2.3 \%$ & & & & & & & \\
\hline Filter & $1.0 \%$ & $0.9 \%$ & $0.3 \%$ & $0.4 \%$ & $0.2 \%$ & $0.2 \%$ & $0.5 \%$ & $0.1 \%$ & $0.06 \%$ & $0.07 \%$ & $0.01 \%$ & $0.01 \%$ \\
\hline Total random flux error & $1.1 \%$ & $1.1 \%$ & $0.7 \%$ & $0.8 \%$ & $3.1 \%$ & $0.3 \%$ & $0.5 \%$ & $0.6 \%$ & $0.2 \%$ & $0.3 \%$ & $0.3 \%$ & $1.2 \%$ \\
\hline & & in ev & & & & & & & & & & \\
\hline Total $\mathrm{Tr}$ error $(\mathrm{Tr}=50 \mathrm{eV})$ & $2.7 \%$ & 1 & & & & & & & & & & \\
\hline Total $\operatorname{Tr}$ error $(\mathrm{Tr}=100 \mathrm{eV})$ & $1.6 \%$ & 2 & & & & & & & & & & \\
\hline Total Tr error $(\mathrm{Tr}=200 \mathrm{eV})$ & $1.2 \%$ & 2 & & & & & & & & & & \\
\hline Total $\mathrm{Tr}$ error $(\mathrm{Tr}=300 \mathrm{eV})$ & $0.7 \%$ & 2 & & & & & & & & & & \\
\hline
\end{tabular}

Table 2: Error values by channel and the resultant error in radiation temperature measurements. 


\section{$\underline{\text { Response Functions }}$}

All of the calibration measurements are used to create the channel response function. The spectral response of the XRDs is multiplied by the reflectance of the mirrors and transmittance of the filters for each channel to calculate the response functions (V/GW*eV, assuming $50 \mathrm{ohms}$ input impedance). These functions determine the contribution of each channel to the Planckian in the unfold routine and thus, the spectral distribution of the soft x-rays from the target. Examples of the response functions are plotted in figure 4.
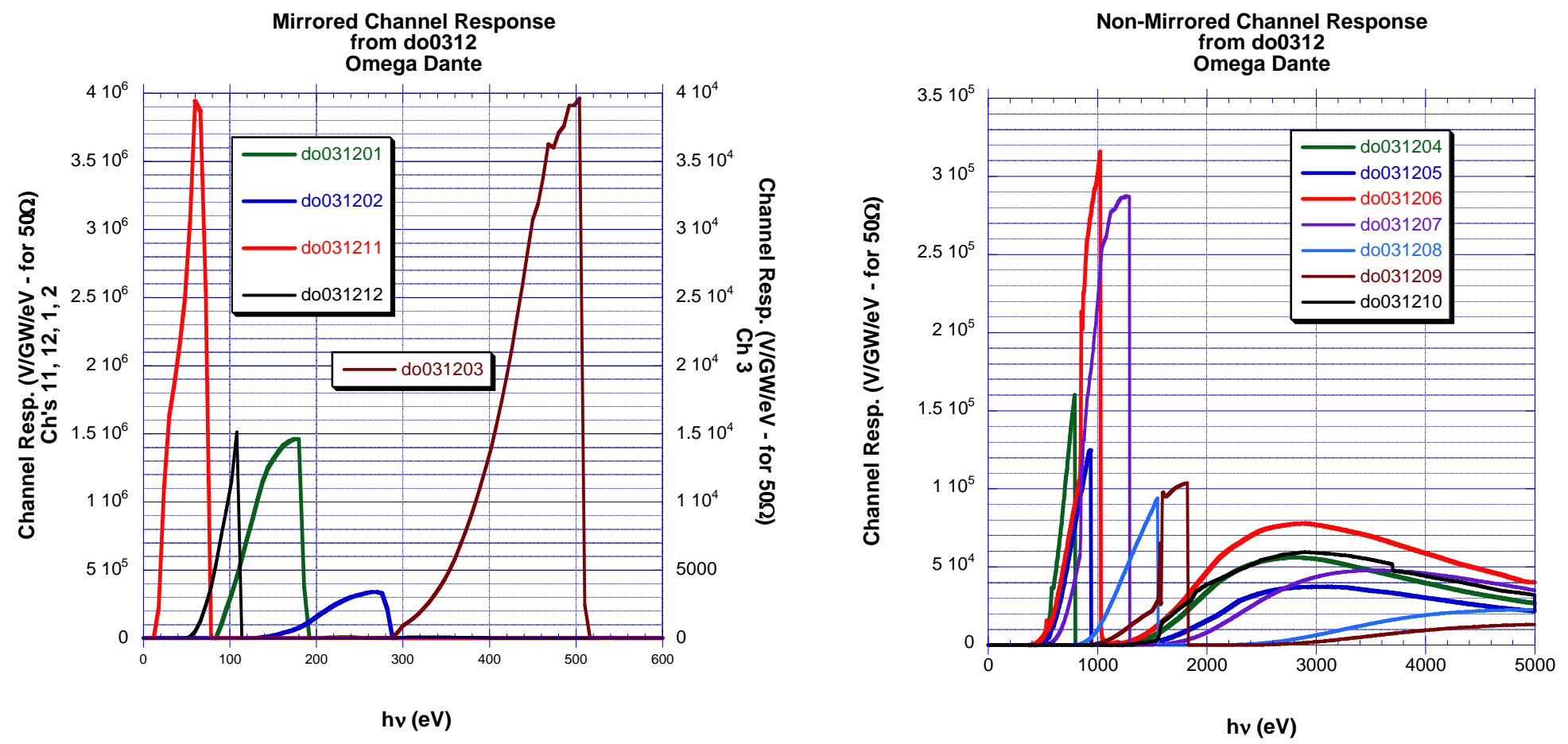

Figure 4: Results of the calibration effort - the channel response functions. Mirror channels have much thinner and lower $Z$ filters than higher energy channels and therefore have higher response values, with the exception of channel 3 that is comparable to the non-mirror channels. Ch 3 is plotted on the right Mirror Channel axis - the channel response is too small to effectively plot with the others. The mirrors effectively cut off $<1 \mathrm{keV}$ energies, where the filters begin to transmit, for better channel definition 